\title{
Comparison of SeaWiFS and MODIS time series of inherent optical properties for the Adriatic Sea
}

\author{
F. Mélin \\ European Commission - Joint Research Centre, Institute for Environment and Sustainability, TP272, via Fermi, 2749, 21027, \\ ISPRA, Italy
}

Received: 10 December 2010 - Published in Ocean Sci. Discuss.: 24 January 2011

Revised: 4 May 2011 - Accepted: 24 May 2011 - Published: 27 May 2011

\begin{abstract}
Time series of inherent optical properties (IOPs) derived from SeaWiFS and MODIS are compared for the Adriatic Sea. The IOPs are outputs of the Quasi-Analytical Algorithm and include total absorption $a$, phytoplankton absorption $a_{\mathrm{ph}}$, absorption associated with colored detrital material (CDM) $a_{\mathrm{cdm}}$, and particle backscattering coefficient $b_{\mathrm{bp}}$. The average root-mean square difference $\Delta$ computed for log-transformed distributions decreases for $a$ from 0.084 at $412 \mathrm{~nm}$ to 0.052 at $490 \mathrm{~nm}$, is higher for $a_{\mathrm{ph}}(443)(0.149)$ than for $a_{\mathrm{cdm}}$ (443) (0.071), and is approximately 0.165 for $b_{\mathrm{bp}}$ at various wavelengths. The SeaWiFS $a$ at 443 and $490 \mathrm{~nm}, a_{\mathrm{ph}}$ at $443 \mathrm{~nm}$ and $b_{\mathrm{bp}}$ are on average higher than the MODIS counterparts. Statistics show significant variations in space and time. There is an overall increasing gradient for $\Delta$ associated with the absorption terms from the open southern and central Adriatic to the northwest part of the basin, and a reversed gradient for the particulate backscattering coefficient. For time series analysis, only $a(412)$ and $a_{\mathrm{cdm}}$ (443) currently present an unbiased continuity bridging the SeaWiFS and MODIS periods for the Adriatic Sea.
\end{abstract}

\section{Introduction}

The Adriatic Sea, a sub-basin of the Mediterranean Sea, has been selected as a basin of interest for development and assessment of ocean colour products in the framework of the European COastal-shelf sea OPerational observing and forecasting system (ECOOP) project, in view of improving the use of remote sensing data in regional and coastal seas. This choice has been mainly motivated by two reasons. In spite of a relatively small size, the Adriatic Sea offers a diversity of bio-optical properties, with a general gradient from

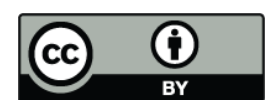

Correspondence to: F. Mélin (frederic.melin@jrc.ec.europa.eu) oligotrophic to eutrophic conditions from south to north (Zavatarelli et al., 1998) with the exception of eutrophic conditions near the southeastern corner (Marini et al,, 2010), the seasonal occurrence of a phytoplankton bloom in the southern gyre (e.g., Santoleri et al., 2003) and the local influence of river inputs or bottom re-suspension. It is thus an interesting test basin for assessing and developing ocean colour satellite products. Concurrently such products are really needed as a monitoring asset since the basin, particularly its northern part, is considered under severe anthropogenic pressure (Coll et al., 2009; Diaz and Rosenberg, 2008; Halpen et al., 2008; Lotze et al., 2006), and has been showing noticeable changes in the recent past, like a decrease of nutrient concentration (ammonia and phosphate, Solidoro et al. 2009) and minima in the Po River outflow after 2002 (Zanchettin et al., 2008). Using ocean colour data, Vantrepotte and Mélin (2010) documented an increasing trend in the blue-to-green ratio of water-leaving radiance in the northern Adriatic, and a corresponding decrease in the average level of chlorophyll $a$ concentration ( $\mathrm{Chl} a$ ) has been documented (Mélin et al., 2011; Mozetič et al., 2010).

In that context, quality and continuity of data records derived from successive satellite missions are needed. Among the suite of potential satellite products, Chl $a$ has had a primary role for various reasons, not the least its inclusion in monitoring programs with field measurements. Standard satellite products have shown large uncertainties in coastal regions and marginal seas, including the Adriatic Sea (Mélin et al. 2003, 2007b), and regional algorithms have been proposed to produce improved data (e.g., for the northern Adriatic, D'Alimonte and Zibordi, 2003). In the framework of ECOOP, an improved Chl $a$ time series has been constructed and analysed (Mélin et al., 2011). Another avenue to generate quality data records is the use of (semi-) analytical bio-optical algorithms that are thought to be less sensitive to regional variations in optical properties. These algorithms provide a more complete characterization of the

Published by Copernicus Publications on behalf of the European Geosciences Union. 
optically significant constituents by calculating a set of inherent optical properties (IOPs) that can be used for various applications. Specifically, phytoplankton absorption is another proxy for algal biomass and can be used in models of primary production (e.g., Lee et al., 1996); absorption by chromophoric dissolved organic matter (CDOM) and particle backscattering support the study of dissolved or particulate organic carbon, and suspended particulate material (Ferrari, 2000; Loisel et al., 2002; D'Sa et al., 2007); IOPs can also be used for modelling the propagation of light in the water column (Lee et al., 2007).

This study specifically focuses on the aspect of continuity of time series of IOPs derived from successive satellite missions, namely the Sea-viewing Wide Field-of-view Sensor (SeaWiFS, Hooker et al. 1992), and the Moderate Resolution Imaging Spectroradiometer (MODIS, Esaias et al. 1998) on board Aqua, with the objective of assessing the differences existing between the IOP records associated with these two missions. After introducing the data and methods, the differences are first analysed at the scale of the basin. Then these differences are discussed in terms of their temporal and spatial variations.

\section{Data and methods}

\subsection{The Adriatic basin}

The geographical scope of the study is the Adriatic Sea over the domain $39^{\circ}-46^{\circ} \mathrm{N}, 11^{\circ} 30^{\prime}-22^{\circ} \mathrm{E}$ (Fig. 1). The overall surface circulation is cyclonic with permanent or seasonal sub-basin gyres and coastal currents (Artegiani et al., 1997). The southward western Adriatic current is particularly significant for its transport of constituents discharged by rivers found along the northwest coast (Harris et al., 2008) and consequent impact in terms of biogeochemistry and optics (Penna et al., 2004; Marini et al., 2008; Mélin et al., 2011). Being surrounded by populated land masses, the atmosphere is strongly influenced by continental aerosols (e.g., Mélin et al., 2006) in addition to marine aerosols and dust transport from Africa. The diversity in marine optical properties is thus combined by fairly variable atmospheric conditions that are inputs to the atmospheric correction process.

In a previous study associated with ECOOP, an opticallybased classification of the Adriatic Sea has been proposed (Mélin et al., 2011). Using two optical data sets, representative of open ocean clear water conditions and of Adriatic coastal waters (Zibordi et al., 2002), two associated classes ( 1 and 2, respectively) have been defined. Then, satellite data have been used to calculate a class index (varying between 1 and 2) for each daily map using the novelty detection technique (D'Alimonte et al., 2003; Mélin et al., 2011). The class index multi-year average (Fig. 1) shows that most of the basin is associated with Class 1 waters, whereas Class 2 waters are restricted to the northwest region, a thin stripe

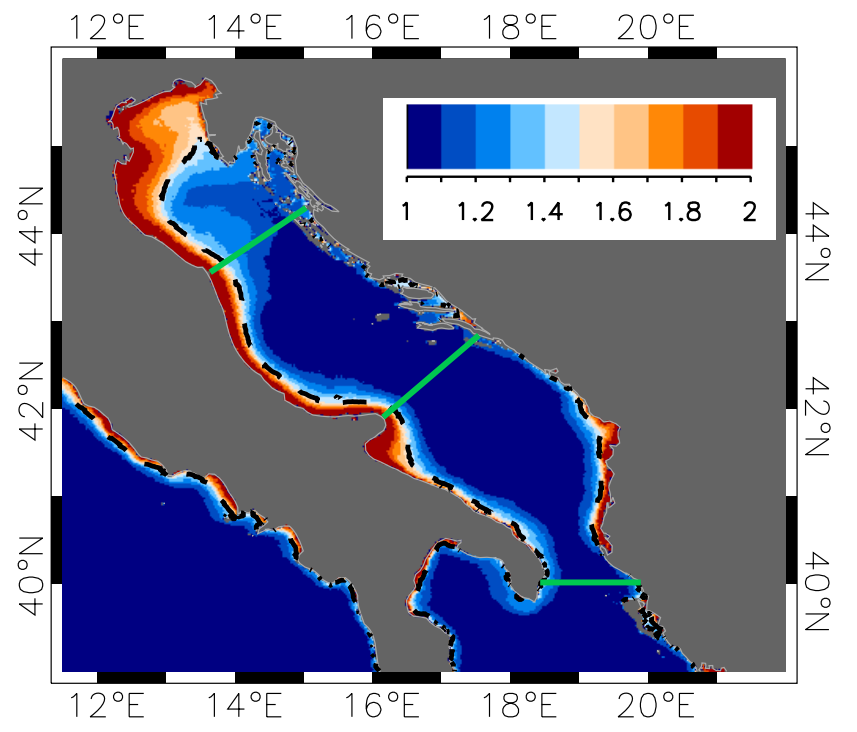

Fig. 1. Adriatic Sea domain of analysis. The color represents a multi-annual average of an optical index varying between 1 and 2 and quantifying a membership to optical classes 1 or 2 (see text for definition). The dashed black line is the 1.5 isoline separating the regions most often classified as Class 1 or 2. Green lines partition the Adriatic Sea into northern, central and southern regions (NADRS, CADRS, and SADRS, respectively).

along the western boundary (Italian coast) and the southeast of the basin (coast of Albania). Moreover, the separation between waters most often classified as Class 1 or 2 (illustrated by the 1.5 -index isoline highlighted by the dashed black line in Fig. 1) is fairly sharp. Separate statistics will be given for these two optical regions as well as for three sub-basins, northern, central and southern Adriatic (NADRS, CADRS, SADRS, respectively).

\subsection{Satellite products}

The analyzed satellite products are part of the E.C. Joint Research Centre archive for the European seas ${ }^{1}$, with the specific window of the Adriatic Sea considered in the framework of the ECOOP project. The main source of the level1A satellite imagery is the Goddard Space Flight Center of the US National Aeronautics and Space Administration (NASA). For an analysis at regional scale and a comparison with MODIS products at a comparable resolution, only full-resolution imagery is considered for SeaWiFS (the socalled Local Area Coverage, LAC, data). This series covers the period September 1997 to December 2004, that marks the end of the unrestricted distribution of the LAC data collected by receiving stations, and the end of a continuous and homogeneous coverage by LAC imagery for European seas. The record is completed by on-board recorded LAC data after April 2005 that allow a regular coverage of the

\footnotetext{
${ }_{1}^{1}$ illustrated on http://oceancolour.jrc.ec.europa.eu
} 
northern Adriatic, and by images received by three ground stations of the European Space Agency for most of 2006 and 2007. MODIS Aqua data are available from July 2002 to the present.

All satellite images are processed with the SeaWiFS Data Analysis System (SeaDAS) version 6.1 (Fu et al., 1998). Its primary output is the spectrum of normalized remote sensing reflectance $R_{\mathrm{RS}}(\lambda)$ obtained after atmospheric correction (Franz et al. 2007 and references therein, Ahmad et al. 2010), and expressed at 412, 443, 490, 510, 555 and $670 \mathrm{~nm}$ for SeaWiFS, and 412, 443, 488, 531, 547 and $667 \mathrm{~nm}$ for MODIS. The derived products of interest here are the following IOPs: total absorption $a$, phytoplankton absorption $a_{\mathrm{ph}}$, the absorption associated with colored detrital material (CDM) $a_{\mathrm{cdm}}$ that is the sum of the absorption due to CDOM $a_{\text {cdom }}$ and non-pigmented particles $a_{\mathrm{npp}}$, and the backscattering due to particles $b_{\mathrm{bp}}$. All products are re-mapped on a regular grid with an approximate spatial resolution of 2-km. The superscripts $\mathrm{S}$ and A will indicate products associated with SeaWiFS and MODIS-Aqua, respectively.

\subsection{Bio-optical algorithm}

The IOPs are computed with the Quasi-Analytical Algorithm (QAA, version 5, Lee et al., 2002). The algorithm first derives the total absorption and backscattering. The model assumes that total absorption is due to pure sea water, phytoplankton, CDOM and non-pigmented particles, with the latter two contributions combined into $a_{\mathrm{cdm}}$, considering the difficulty of discriminating these absorption terms that are characterized by a broadly comparable spectral shape (exponential decay with increasing wavelength). Separating $a_{\mathrm{ph}}$ and $a_{\mathrm{cdm}}$ is done by assuming that $a_{\mathrm{cdm}}(\lambda)$ is proportional to $\mathrm{e}^{-S \lambda}$ with $S$ approximately equal to $0.015 \mathrm{~nm}^{-1}$ and that $a_{\mathrm{ph}}(412) / a_{\mathrm{ph}}(443)$ is an empirical function of the blue-togreen reflectance ratio. The spectral shape of $b_{\mathrm{bp}}$ is expressed as $\lambda^{-\eta}$, with $\eta$ also an empirical function of a blue-to-green reflectance ratio. In practice,

$\eta=2\left(1-1.2 \cdot e^{-0.9 R}\right)$

where $R$ is the ratio of $r_{\mathrm{rs}}$ at 443 and $547 \mathrm{~nm}$, and $r_{\mathrm{rs}}$ is the below-water remote sensing reflectance linked to the abovewater $R_{\mathrm{RS}}$ by:

$r_{\mathrm{rs}}=R_{\mathrm{RS}} /\left(0.52+1.7 R_{\mathrm{RS}}\right)$

The outputs of the QAA algorithm are expressed at the various SeaWiFS and MODIS wavelengths. In practice, a direct comparison between the two sets of products will be done for $a(412)$ and $a(443), a_{\mathrm{ph}}(443)$ and $a_{\mathrm{cdm}}(443)$, as well as between $a^{\mathrm{S}}(490)$ and $a^{\mathrm{A}}(488)$, assuming that the 2-nm spectral difference does not significantly impact the comparison statistics. Finally, the comparison is done between the backscattering coefficients after expressing the MODIS values at $\lambda_{\mathrm{A}}$ onto the closest SeaWiFS wavelength $\lambda_{\mathrm{S}}$, if needed:

$b_{\mathrm{bp}}\left(\lambda_{\mathrm{S}}\right)=b_{\mathrm{bp}}\left(\lambda_{\mathrm{A}}\right)\left(\frac{\lambda_{\mathrm{A}}}{\lambda_{\mathrm{S}}}\right)^{\eta}$ using the associated $R_{\mathrm{RS}}$ values to calculate $\eta$ (Eqs. 1 and 2). This spectral correction, applied to derive synthetic MODIS values $b_{\mathrm{bp}}^{\mathrm{A}}(490)$ and $b_{\mathrm{bp}}^{\mathrm{A}}(555)$, is actually very small. For instance, between 547 and $555 \mathrm{~nm}$, the correction factor varies between 1 and 0.97 for $\eta$ of 0 and 2, respectively.

\subsection{Methods of comparison}

Each pair of daily maps for the period July 2002 to December 2006 is searched for concurrent values valid for both satellite missions. The associated data sets of $R_{\mathrm{RS}}$ and IOPs are then accumulated at the scale of each grid point, or for all or part of the basin. When the statistics are computed at the scale of each grid point, the time period is restricted to 2003, 2004, 2006 and 2007, that are complete years with fairly homogeneous coverage, in order to avoid any bias on the obtained spatial distributions that could be introduced by a possible seasonal dependence.

Considering an ensemble of $N$ matching pairs, $\left(s_{i}\right)_{i=1, N}$ and $\left(a_{i}\right)_{i=1, N}$ associated with SeaWiFS and MODIS, respectively, the unbiased percent differences between the two distributions are expressed as:

$$
\begin{gathered}
|\psi|=100 \frac{1}{N} \sum_{i=1}^{N} \frac{2\left|a_{i}-s_{i}\right|}{s_{i}+a_{i}} \\
\psi=100 \frac{1}{N} \sum_{i=1}^{N} \frac{2\left(a_{i}-s_{i}\right)}{s_{i}+a_{i}}
\end{gathered}
$$

with $|\psi|$ and $\psi$ respectively the mean absolute relative difference and mean relative difference (or bias). Log-transformed statistics (base-10) are defined by:

$$
\begin{aligned}
& \Delta=\sqrt{\frac{1}{N} \sum_{i=1}^{N}\left(\log \left(a_{i}\right)-\log \left(a_{i}\right)\right)^{2}} \\
& \delta=\frac{1}{N} \sum_{i=1}^{N}\left(\log \left(a_{i}\right)-\log \left(s_{i}\right)\right)
\end{aligned}
$$

Across the manuscript, positive (negative) values for $\psi$ or $\delta$ indicate that the MODIS derived distribution is on average higher (lower) than the SeaWiFS counterpart. The first moments (including skewness and kurtosis) of the distributions associated with these matching pairs are also computed to better characterize the data sets.

\section{Results}

\subsection{General statistics}

To provide background information on the actual IOP values, Fig. 2 illustrates the full monthly time series of selected IOPs independently derived from SeaWiFS and MODIS and averaged for the sub-basins NADRS, CADRS and SADRS. 

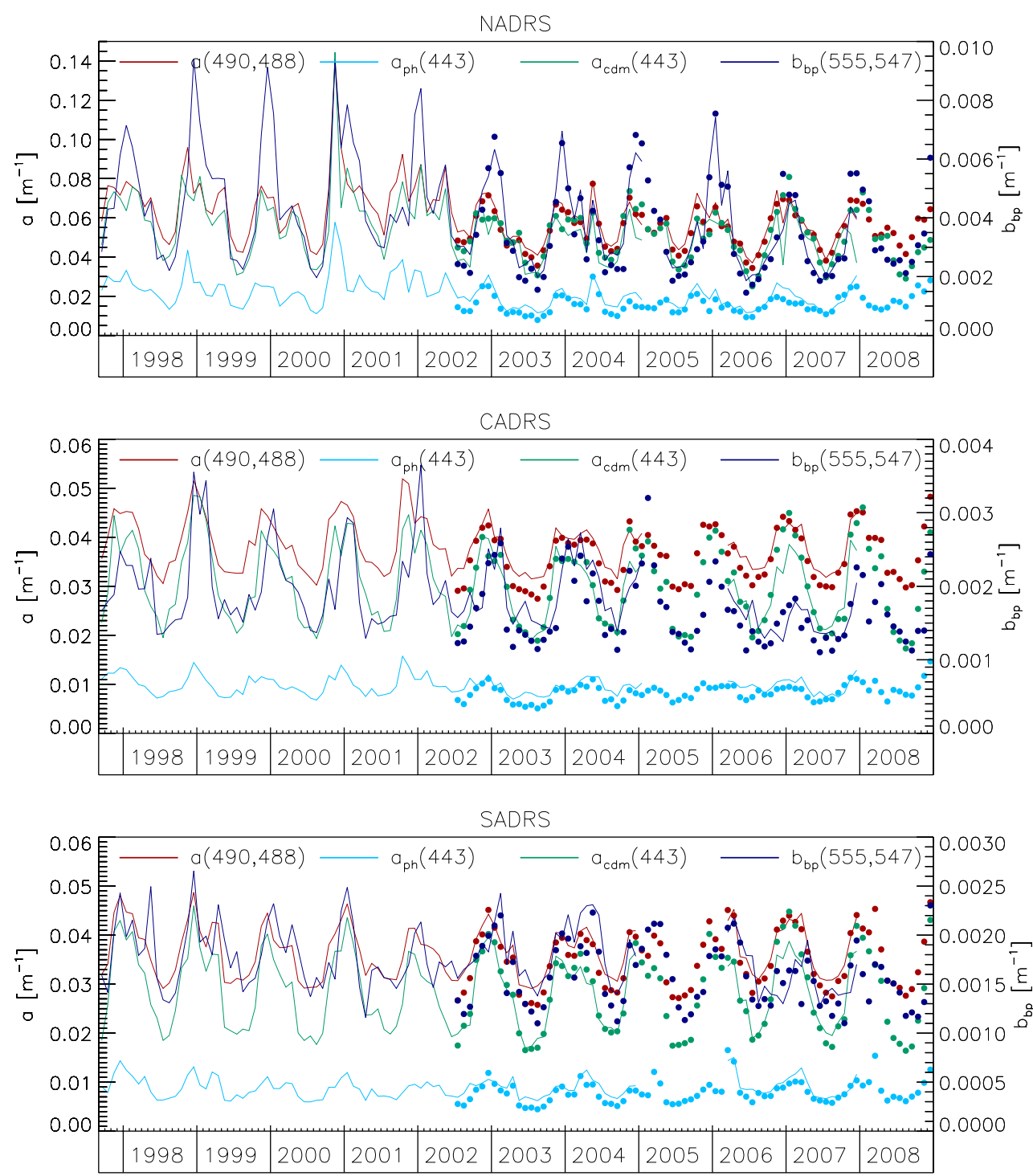

Fig. 2. Monthly time series averaged over the sub-basins NADRS, CADRS, and SADRS for SeaWiFS/MODIS $a^{\mathrm{S}}(490), a^{\mathrm{A}}(488), a_{\mathrm{ph}}(443)$, $a_{\mathrm{cdm}}(443), b_{\mathrm{bp}}^{\mathrm{S}}(555)$ and $b_{\mathrm{bp}}^{\mathrm{A}}(547)$. SeaWiFS and MODIS values are represented by lines and circles, respectively.

Three main comments can be made from these series. First, they confirm the generally higher values displayed by the IOPs in the northern part of the basin (Mélin et al., 2011), and show seasonal maxima mostly centred around winter. Then in NADRS, the average IOP values appear lower after 2002, consistently with results obtained for Chl $a$ (Mozetič et al., 2010; Mélin et al., 2011).

The average number of matching pairs of SeaWiFS and MODIS products for the years 2003, 2004, 2006 and 2007 is 233 (standard deviation, s.d., 51). If the analysis is restricted to grid points with at least 100 matching pairs $(96 \%$ of the basin grid points), a logarithm transformation of the data appears as an appropriate statistical model based on the values of skewness and kurtosis that are largely smaller for log-transformed distributions. For the considered absorption terms and for both SeaWiFS and MODIS, skewness is on average 2.3 to 3.7 times smaller after log-transformation, and kurtosis is usually smaller by an order of magnitude. For $b_{\mathrm{bp}}$, skewness is smaller by a factor larger than 10 , and kurtosis by approximately a factor 7 , for log-transformed distributions. Therefore, a framework of log-normality is preferred, consistently with previous results and analyses associated with Chl $a$ or IOP distributions (Campbell, 1995; Djavidnia et al., 2010; Mélin, 2010), and most statistics presented subsequently are those related to log-transformed distributions, even though the general values of $|\psi|$ and $\psi$ are given for completeness. 

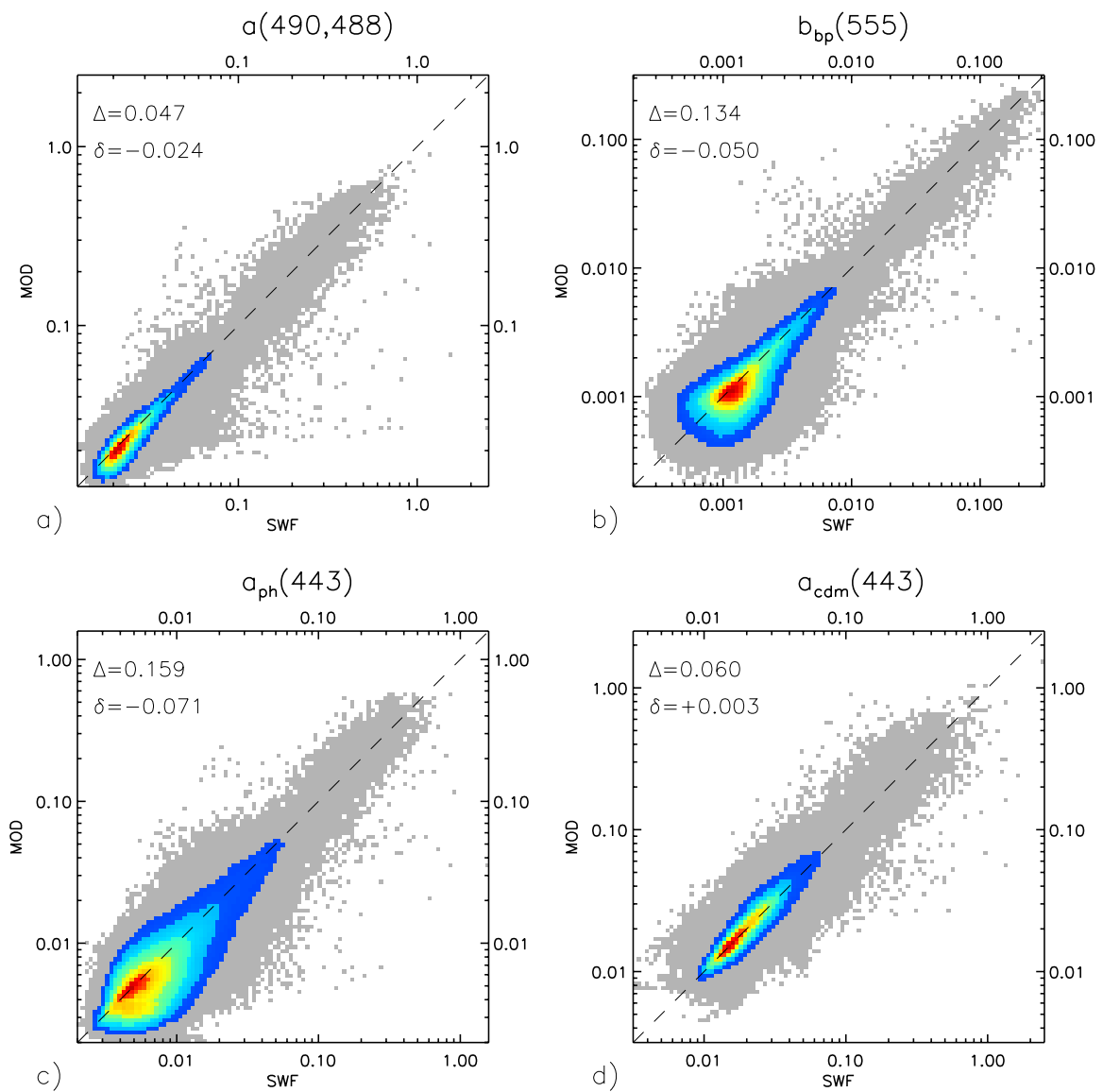

Fig. 3. Comparison of SeaWiFS and MODIS IOPs $(N=5242738)$ for (a) $a^{\mathrm{S}}(490)$ versus $a^{\mathrm{A}}(488)$, (b) $b_{\mathrm{bp}}(555)$, (c) $a_{\mathrm{ph}}(443)$, and (d) $a_{\mathrm{cdm}}(443)$. Colors show the density of matching pairs in the two-dimensional histogram, with grey representing bins associated with less than $1 \%$ of the maximum density.

Figure 3 plots all available matching pairs for $a^{\mathrm{S}}(490)$ versus $a^{\mathrm{A}}(488), b_{\mathrm{bp}}(555), a_{\mathrm{ph}}(443)$ and $a_{\mathrm{cdm}}(443)$ (more than 5 million pairs). A general result is that the IOPs compare reasonably well across their entire range even though the scatter of points tend to increase at the low end of values, particularly for $b_{\mathrm{bp}}(555)$ and $a_{\mathrm{ph}}(443)$. The SeaWiFS-derived values appear higher in the interval of low IOP values, except for $a_{\mathrm{cdm}}(443)$ that is associated with a negligible bias. The root-mean-square difference $\Delta$ is also significantly smaller for $a_{\mathrm{cdm}}(443)$ than for $a_{\mathrm{ph}}(443)$ (0.060 versus 0.159$)$. In the following sub-section, the spatial distribution of the differences are presented.

\subsection{Spatial variations}

The spatial distribution of $\Delta$ and $\delta$ are shown on Figs. 4 and 5 , respectively. Again, these maps are constructed with data from 2003, 2004, 2006 and 2007, with a total of 1454 pairs of daily maps. The average values of statistics are presented in Table 1 . These are calculated using the grid points with more than 100 matching pairs, for the entire basin as well as for the regions most often classified as Class 1 or Class 2 using the optical classification introduced in Sect. 2.1 (Fig. 1; hereafter these regions will be simply referred to as Class 1 or Class 2 waters). The averages of $\Delta$ and $\delta$ differ slightly than those displayed in Fig. 3 because they are spatial averages of these quantities calculated for each grid point.

The distributions of $\Delta$ and $\delta$ obtained comparing $a^{\mathrm{S}}(490)$ and $a^{\mathrm{A}}(488)$ are fairly homogeneous, with average values of approximately 0.05 and -0.02 (Figs. $4 \mathrm{a}$ and $5 \mathrm{a}$ ). Close to the coast, particularly in the northwest region, $\Delta$ increases with a bias that locally becomes slightly positive. This explains why for Class 2 waters the average $\Delta$ is slightly higher and $\delta$ is less negative $(-0.10)$ (Table 1$)$. A comparable spatial distribution is found for $a(412)$ (not shown), but with higher $\Delta$ values particularly in coastal waters ( $\Delta$ equal to 0.168 for Class 2 regions). The associated bias is very close to 0 for most of the basin, except for positive values near the northwestern coast (exceeding +0.04 ). Statistics for $a(443)$ are found intermediate to those obtained at $412 \mathrm{~nm}$ and $488 / 490 \mathrm{~nm}$ (with an average bias of -0.012 , Table 1 ). 

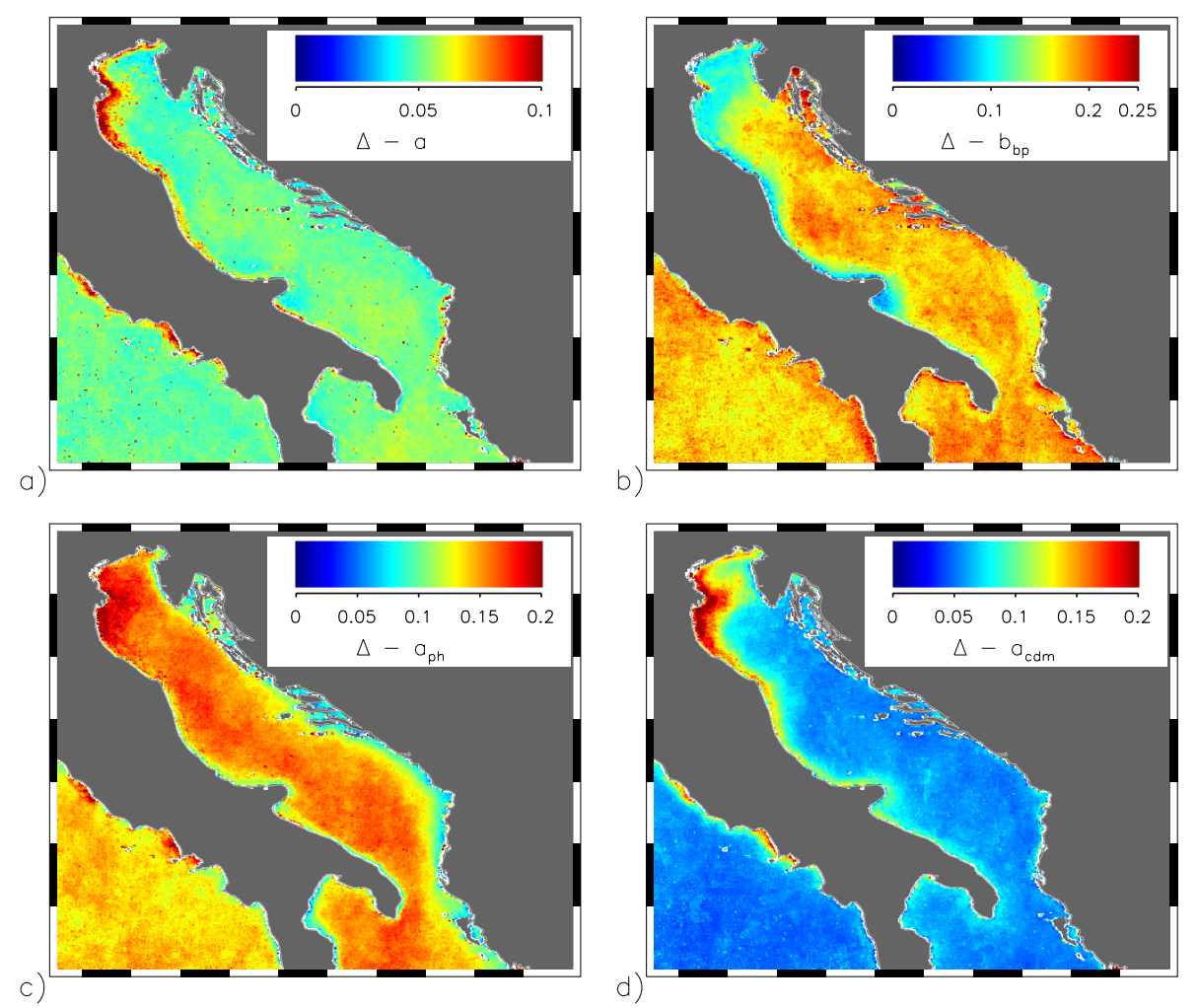

Fig. 4. Maps of $\Delta$ obtained comparing (a) $a^{\mathrm{S}}(490)$ versus $a^{\mathrm{A}}(488)$, (b) $b_{\mathrm{bp}}(555)$, (c) $a_{\mathrm{ph}}(443)$, and (d) $a_{\mathrm{cdm}}(443)$ (using $N=1454$ days).

Table 1. Average statistics calculated using the grid points with more than 100 matching pairs for the entire basin (ADRS), as well as for the regions most often classified as optical Class 1 or Class 2 (see text for definition). $|\psi|$ and $\psi$ are in expressed in $\%$.

\begin{tabular}{c|cccc|cccc|cccc}
\hline & \multicolumn{4}{|c}{ ADRS } & \multicolumn{1}{c}{ Class 1 } & \multicolumn{4}{c}{ Class 2 } \\
& $\Delta$ & $\delta$ & $|\psi|$ & $\psi$ & $\Delta$ & $\delta$ & $|\psi|$ & $\psi$ & $\Delta$ & $\delta$ & $|\psi|$ & $\psi$ \\
\hline$a(412)$ & 0.084 & +0.006 & 12 & +1 & 0.068 & +0.002 & 10 & +1 & 0.168 & +0.024 & 23 & +5 \\
$a(443)$ & 0.060 & -0.012 & 10 & -3 & 0.054 & -0.015 & 9 & -3 & 0.086 & +0.003 & 14 & +1 \\
$a(490)$ & 0.052 & -0.021 & 9 & -5 & 0.051 & -0.023 & 9 & -5 & 0.058 & -0.010 & 9 & -2 \\
$a_{\mathrm{ph}}(443)$ & 0.149 & -0.060 & 25 & -14 & 0.148 & -0.062 & 25 & -14 & 0.155 & -0.053 & 26 & -12 \\
$a_{\mathrm{cdm}}(443)$ & 0.071 & +0.006 & 12 & +1 & 0.060 & +0.003 & 10 & +1 & 0.124 & +0.025 & 20 & +6 \\
$b_{\text {bp }}(412)$ & 0.163 & -0.055 & 27 & -12 & 0.172 & -0.059 & 28 & -13 & 0.116 & -0.035 & 19 & -8 \\
$b_{\text {bp }}(490)$ & 0.164 & -0.051 & 27 & -11 & 0.174 & -0.056 & 29 & -12 & 0.117 & -0.029 & 19 & -7 \\
$b_{\text {bp }}(555)$ & 0.166 & -0.049 & 27 & -11 & 0.175 & -0.053 & 29 & -12 & 0.118 & -0.025 & 19 & -6 \\
\hline
\end{tabular}

As anticipated by Fig. 3, the differences are higher for $a_{\mathrm{ph}}(443)$ than for $a_{\mathrm{cdm}}(443)$ across most of the basin (basin averages of 0.149 and 0.071 , respectively), except close to the Po River outlet (Figs. 4c, d). The distribution of $\Delta$ obtained for $a_{\mathrm{cdm}}(443)$ is characterized by a sharp gradient from the northwest region ( $\Delta$ as high as 0.2 ) to the centre of the basin (approximately 0.06 ), and the average $\Delta$ is higher for Class 2 waters (Table 1). The bias associated with $a_{\mathrm{ph}}(443)$ is negative across the basin (average -0.060 ), while it is close to 0 for $a_{\mathrm{cdm}}(443)$ (+0.003 for Class 1 waters) with an increase in the coastal northwestern region.
Contrary to the absorption terms, $\Delta$ is lower in the northwestern region for $b_{\mathrm{bp}}$, with statistics very similar between 412 and $555 \mathrm{~nm}$ (Table 1). The bias is mostly negative across the basin, except for an opposite sign in some areas very near the coast. As a consequence, $\delta$ is halved between Class 1 and Class 2 waters. There is a slight increase of the bias (meaning, more negative) for short wavelengths, pointing to differences in the calculation of $\eta$ that defines the spectral shape of $b_{\mathrm{bp}}(\lambda)$. 

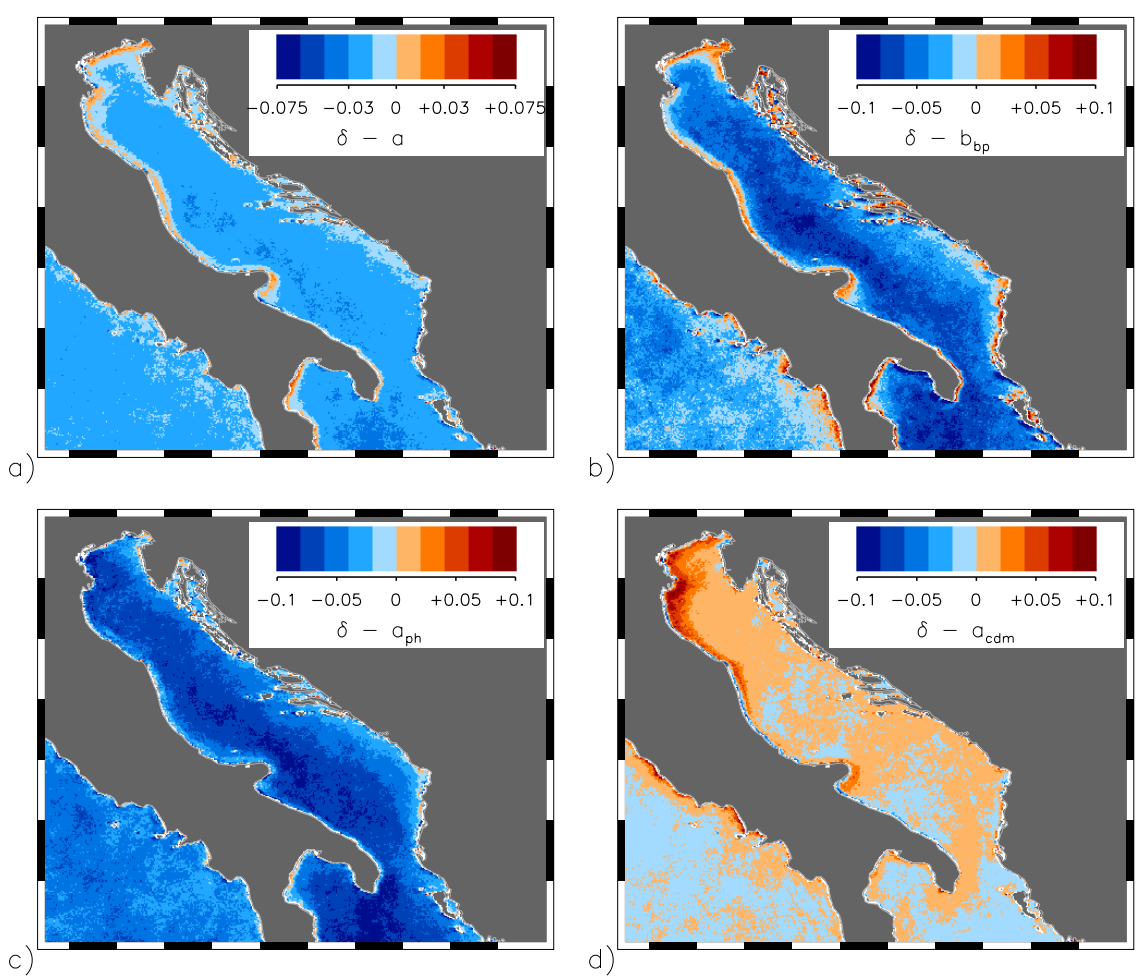

Fig. 5. Same as Fig. 4 for $\delta$.
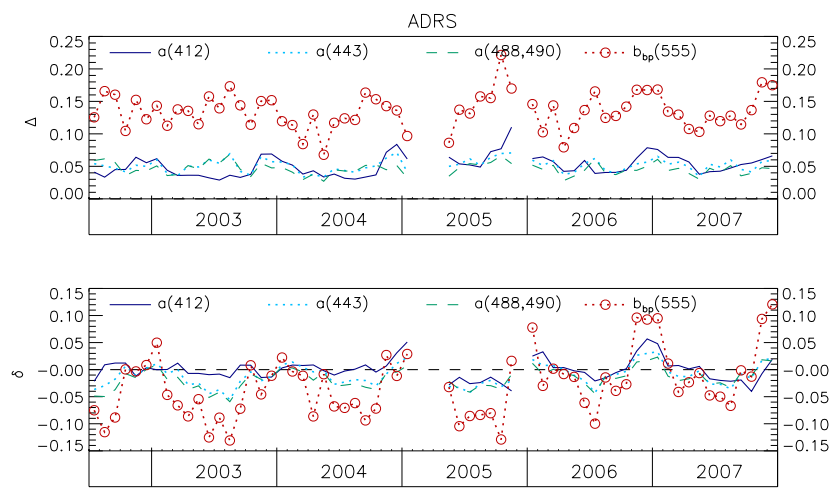

Fig. 6. Monthly time series of $\Delta$ (upper panel) and $\delta$ (lower panel) obtained from the comparison conducted with $a(412), a(443)$, $a^{\mathrm{A}}(488)$ versus $a^{\mathrm{S}}(490)$, and $b_{\mathrm{bp}}(555)$.

\subsection{Temporal variations}

Statistics are calculated using the matching pairs accumulated for each month over the basin. The resulting time series of $\Delta$ and $\delta$ are shown in Fig. 6 for total absorption and $b_{\text {bp }}(555)$ and Fig. 7 for $a_{\mathrm{ph}}(443)$ and $a_{\mathrm{cdm}}(443)$. Monthly records are displayed only if there are at least 1000 matching pairs for the month. This number of records tend to be lowest in 2005 when the coverage, if any, is restricted to the northern Adriatic Sea.

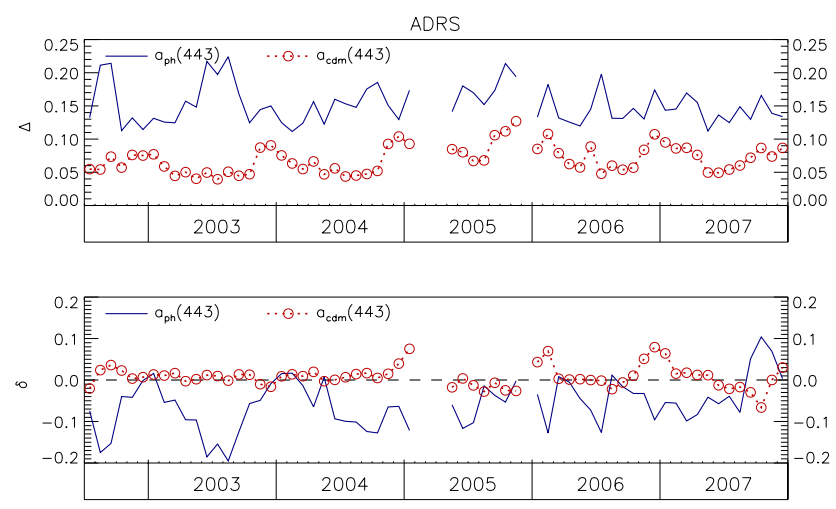

Fig. 7. Same as Fig. 6 for $a_{\mathrm{ph}}(443)$ and $a_{\mathrm{cdm}}(443)$.

The series of $\Delta$ for the absorption terms $a$ are mostly in the interval 0.035-0.06, with some time dependence. For instance, the $\Delta$ values appear higher in winter for $a(412)$. Conversely, the bias found for $a(412)$ is rather stable in time, with the exception of a positive peak in the winter 20062007. The biases associated with $a(443)$ and $a(488,490)$ are much in phase and found to be negative in the spring-summer period of each year, and close to 0 the rest of the year with positive values in the winter 2006-2007. The $\Delta$ series observed for $b_{\mathrm{bp}}(555)$ display fairly large variations but with no obvious seasonality (Fig. 6). On the contrary, $\delta$ show minima in each spring-summer, and positive values at the end of 
2006 and 2007. The results are generally valid for the three sub-basins.

The values $\Delta$ associated with $a_{\mathrm{cdm}}(443)$ tend to be higher in winter of each year (Fig. 7), even though the bias remains rather constant (and close to 0 ). Conversely, $\Delta$ found for $a_{\mathrm{ph}}(443)$ shows a clear peak only in the summer of 2002 and 2003, associated with a large negative bias (below -0.15 from June to August 2003). The values of $\delta$ for $a_{\mathrm{ph}}(443)$ are almost always negative except for a positive episode at the end of 2007. From the series obtained for the absorption terms at $443 \mathrm{~nm}$, it is seen that the negative bias observed for the total absorption $a$ is mostly transferred to $a_{\mathrm{ph}}$. The main characteristics of the temporal variability of the statistics are generally maintained for the Adriatic sub-basins. Among the exceptions, the negative peak observed for $\delta$ for $a_{\mathrm{ph}}(443)$ in summer 2003 is followed by a similar peak in the autumn of the following year (2004) only for CADRS and NADRS, whereas the peak is in July 2004 for SADRS with an amplitude half that of August 2003. For $a_{\mathrm{cdm}}(443)$, the seasonal variations of $\Delta$ are clearer for SADRS than in the northern Adriatic.

\section{Discussion and conclusion}

This study has analysed the differences between SeaWiFS and MODIS derived sets of IOPs that are summarized in Table 1. Firstly, it is underlined that the results are only valid for the considered algorithm, QAA, and the Adriatic Sea. Considering that the basin represents diverse and fairly typical optical water types, the comparison statistics might be applicable to other mid-latitude, moderately oligotrophic to moderately turbid, water bodies, but systematic comparisons of multi-mission $R_{\mathrm{RS}}$ and IOP distributions for other regions are required to further investigate this issue.

The differences documented in this work can be compared with validation results relating satellite products and field measurements. In the framework of an algorithm intercomparison effort (IOCCG, 2006) using field data of reflectance and IOPs, the root-mean-square difference $\Delta$ found between QAA outputs and field data has been found equal to 0.17 for $a$ at 412,443 and $490 \mathrm{~nm}, 0.32$ for $a_{\mathrm{ph}}(443)$ and 0.22 for $a_{\mathrm{cdm}}(443)$. More relevant to the Adriatic Sea, validation analyses have been conducted with data regularly collected at the Acqua Alta Oceanographic Tower (AAOT), that is an oceanographic platform located offshore the Venice lagoon (Zibordi et al., 2002; Berthon et al., 2002). From SeaWiFS match-ups identified at the site, $\Delta$ computed with satellite and field data has been estimated as $0.21,0.14$ and 0.12 for $a$ at 412, 443 and $490 \mathrm{~nm}$, respectively (Mélin et al., 2007a), whereas $\Delta$ extracted for the location of AAOT from the average maps of statistics derived in the present work (for example, Fig. $4 \mathrm{a}$ for $a^{\mathrm{S}}(490)$ versus $\left.a^{\mathrm{A}}(488)\right)$ are $0.19,0.09$ and 0.05 , respectively. Satellite QAA products validation analyses conducted for $a_{\mathrm{ph}}(443)$ and $a_{\mathrm{cdm}}(443)$ lead to $\Delta$ values of approximately 0.20 (Mélin et al. 2007a, 2011), whereas $\Delta$ found between SeaWiFS and MODIS for the AAOT location are 0.18 and 0.15 , respectively. Thus, inter-mission differences appear comparable or lower than root-mean-square differences found with respect to field measurements. This further suggests that such an inter-comparison exercise documents differences that may be considered, with due caution, as conservative estimates of the uncertainties associated with the satellite products, and, by providing results with a complete spatial dimension, is thus complementary to validation analyses that are conducted with field observations collected at a few discrete locations.

The relative agreement between the two sets of IOPs is favoured by the fact that SeaWiFS and MODIS products are derived in a consistent manner, i.e., with as many common mission elements as possible, such as a common calibration strategy, atmospheric correction scheme, bio-optical algorithms or binning scheme. Yet, the products show significant differences, that in turn are linked to differences between the respective remote sensing reflectance spectra, the potential sources of which are briefly discussed here. First, differences in the set of spectral bands might still introduce subtle discrepancies in the processing. Then, SeaWiFS and MODIS pixels covering slightly different areas might end up associated with a common grid point, and their time of overpass might be separated by a couple of hours, a shift that can introduce variations in the atmospheric and/or marine constituents. Even if natural variability undoubtedly contributes to part of the observed differences, its share in the difference budget is deemed small. Even in presence of complex mesoscale dynamics in the northwest Adriatic, the associated time and length scales have been estimated as 1-2 days and 10-km, respectively (Mauri and Poulain, 2001), higher than the grid resolution and time differences considered here. Moreover, the temporal variations observed for remote sensing reflectance measured by autonomous radiometry operating at the AAOT site has been shown small during time intervals typical of those separating SeaWiFS and MODIS overpasses (approximately $4 \%$ for $R_{\mathrm{RS}}$ between 412 and $555 \mathrm{~nm}$ ) (Zibordi et al., 2004; Mélin and Zibordi, 2007). Similarly, it has been argued that changes in aerosol optical thickness $\tau_{a}$ between two overpasses is on average less than $10 \%$ (2 to 3 times lower than the differences between SeaWiFS and MODIS $\tau_{a}$ documented by Mélin et al. 2007b). Besides these elements, the uncertainties inherent to the atmospheric correction are likely a large contributor to the differences between the $R_{\mathrm{RS}}$ distributions input to the QAA. Nor can it be excluded that a drift in calibration might affect one product, as is possible for MODIS starting in 2006 (Maritorena et al., 2010), even though the time series of differences presented here do not allude to an obvious long-term trend.

This being said, the SeaWiFS and MODIS records of $R_{\mathrm{RS}}$ appear fairly consistent: using the same set of matching pairs presented in Fig. 3 for IOPs, $|\psi|$ is in the range $7 \%$ to $12 \%$ for the spectral range $412-555 \mathrm{~nm}$, with a bias between 
$-5 \%$ (at $412 \mathrm{~nm}$ ) and $+2 \%$ (at $555 \mathrm{~nm}$ ) (these comparisons of $R_{\mathrm{RS}}$ account for spectral differences by applying a spectral shift correction described in Mélin et al. 2011). These differences are lower than those found for the Adriatic Sea by Mélin et al. (2009) with a previous version of SeaDAS, bearing testimony to improvements in the atmospheric correction scheme with the inclusion of updated aerosol models and optical modeling in the near-infrared (Ahmad et al., 2010; Bailey et al., 2010). These improvements are translated in a reduction of the negative bias in $R_{\mathrm{RS}}$ often found in coastal regions for the blue bands (for instance compare Zibordi et al., 2009 with Zibordi et al., 2010). It is out of scope of this study to investigate how the differences found for $R_{\mathrm{RS}}$ distributions propagate through the QAA algorithm, a task that is not straightforward. For instance, the negative bias of the MODIS $R_{\mathrm{RS}}^{\mathrm{A}}(412)$ with respect to $R_{\mathrm{RS}}^{\mathrm{S}}(412)$ and the positive value of $\delta$ found for $a(412)$, or the negative biases found for $R_{\mathrm{RS}}$ between 412 and $490 \mathrm{~nm}$ and for $b_{\mathrm{bp}}$ at these wavelengths, seem consistent. Conversely, $\delta$ found for $a$ at 443 and $490 \mathrm{~nm}$ are of the same sign as the slight negative biases found for $R_{\mathrm{RS}}$ at these wavelengths ( $-3 \%$ and $-1 \%$, respectively). In general, a full uncertainty budget of satellite products, going from top-of-atmosphere radiances to derived products such as IOPs is still to be constructed. To investigate actual uncertainties associated with satellite derived IOPs (which entails comparisons with field data), other elements come into play to explain differences, such as the algorithm formulation and its parameters (like specific IOPs or spectral slopes; see also IOCCG 2006), whereas in the current exercise, the algorithm is common to both families of products. Albeit small, data sets ideally suited to support an assessment strategy for satellite derived IOPs are those constituted of satellite matchups for which apparent and inherent optical properties are concurrently available (e.g., Zibordi et al. 2011 for European waters).

Systematic comparisons of satellite products derived from multiple missions are still rare (e.g., see Zhang et al. 2006 for Chl $a$ ), even more so for IOPs. Some studies focusing on Chl $a$ have shown that differences between missionspecific products might exhibit significant variations in space and time (e.g., Djavidnia et al., 2010; Mélin, 2010). Besides quantifying differences between satellite products, the main result of the present work is to show that even at the scale of a small basin such as the Adriatic Sea, indeed there are significant variations in space and time of the comparison statistics. Specifically, there is an overall increasing gradient for $\Delta$ associated with the absorption coefficients from the open southern and central Adriatic to the northwest part of the basin, particularly sharp for $a_{\mathrm{cdm}}(443)$ and less so for $a_{\mathrm{ph}}(443)$, whereas this gradient is reversed for the particulate backscattering coefficient. The value of $\Delta$ for $a_{\mathrm{cdm}}(443)$ tends to peak in winter, and the bias $\delta$ found for $b_{\mathrm{bp}}(555)$ appears more negative in summer than in winter. The results underline that comparison studies need to be performed at appropriate space and time scales.
The overall level of agreement between the SeaWiFS and MODIS IOP distributions might be deemed fairly satisfactory, with $\Delta$ values lower than $\sim 0.16$ (and less than 0.084 for $a$ and $\left.a_{\mathrm{cdm}}(443)\right)$ or $|\psi|$ lower than $27 \%$. For the creation of multi-mission data records, the amplitude of the bias is particularly relevant and it is found lower than 0.06 for $\delta$ or $14 \%$ for $\psi$. Assessing if this agreement is sufficient ultimately depends on the application that a specific user envisions. These time series could already represent a powerful auxiliary for monitoring programs based on in situ sampling conducted on an irregular space and time basis. On the other hand, in view of developing seamless series of ocean colour climate data records amenable to trend detection, this work suggests that it is premature to assume an unbiased continuity between the respective time series, except for $a(412)$ and $a_{\mathrm{cdm}}(443)$ that show low bias values well stable in time. For the other quantities, the MODIS retrievals are on average lower than the SeaWiFS counterparts. The development of multi-mission consistent records of $R_{\mathrm{RS}}$ and IOPs remains a priority requirement to fully realize the potential of ocean colour remote sensing for long-term monitoring activities and climate change research.

Acknowledgements. The authors would like to thank the Ocean Biology Processing Group of NASA for the distribution of the SeaWiFS and MODIS L1A data. The contribution of the European Space Agency is also acknowledged, as directly providing SeaWiFS LAC imagery through three receiving stations for 2006-2007. Eugen Capilna is thanked for his support related to satellite data processing. This work has been partly funded by the EU FP6 ECOOP Project (No. 36355).

Edited by: P. Oddo

\section{References}

Ahmad, Z., Franz, B. A., McClain, C. R., Kwiatkowska, E. J., Werdell, J., Shettle, E. P., Holben, B. N.: New aerosol models for the retrieval of aerosol optical thickness and normalized waterleaving radiances from the SeaWiFS and MODIS sensors over coastal regions and open oceans, Appl. Opt., 49, 5545-5560, 2010.

Artegiani, A., Bregant, D., Paschini, E., Pinardi, N., Raicich, F., and Russo, A.: The Adriatic Sea general circulation. Part II: Baroclinic circulation structure, J. Phys. Oceanogr., 27, 1515-1532, 1997.

Bailey, S. W., Franz, B. A., and Werdell, P. J.: Estimation of nearinfrared water-leaving reflectance for satellite ocean color data processing, Opt. Exp., 18, 7521-7527, 2010.

Berthon, J.-F., Zibordi, G., Doyle, J.-P., Grossi, S., van der Linde, D.,and Targa, C.: Coastal Atmosphere and Sea Time Series (CoASTS): Data analysis. NASA Technical Memorandum 2002206892, 20, 1-25, editd by: Hooker, S. B. and Firestone, E. R. NASA-GSFC, Greenbelt, Maryland, USA, 2002.

Campbell, J. W.: The lognormal distribution as a model for biooptical variability in the sea, J. Geophys. Res., 100, 1323713254, 1995. 
Coll, M., Santojanni, A., Palomera, I., and Arneri, E.: Food-web changes in the Adriatic Sea over the last three decades, Mar. Ecol. Prog. Ser., 381, 17-37, 2009.

D'Alimonte, D. and Zibordi, G.: Phytoplankton determination in an optically complex coastal region using a multilayer perceptron neural network, IEEE Trans. Geosci. Remote Sens., 41, 28612868, 2003.

D’Alimonte, D., Mélin, F., Zibordi, G., and Berthon, J.-F.: Use of the novelty detection technique to identify the range of applicability of the empirical ocean color algorithms, IEEE Trans. Geosci. Remote Sens., 41, 2833-2843, 2003.

Diaz, R. J., Rosenberg, R.: Spreading dead zones and consequences for marine ecosystems, Science, 321, 926-929, 2008.

Djavidnia, S., Mélin, F., and Hoepffner, N.: Comparison of global ocean colour data records. Ocean Sci., 61-76, 2010.

D’Sa, E. J., Miller, R. L., McKee, B. A.: Suspended particulate matter dynamics in coastal waters from ocean color: Application to the northern Gulf of Mexico, Geophys. Res. Lett., 34, L23611, doi:10.1029/2007GL031192, 2007.

Esaias, W. E., Abbott, M. R., Barton, I., Brown, O. B., Campbell, J. W., Carder, K. L., Clark, D. K., Evans, R. H., Hoge, F. E., Gordon, H. R., Balch, W. M., Letelier, R., and Minnett, P. J.: An overview of MODIS capabilities for ocean science observations, IEEE Trans. Geosci. Remote Sens., 36, 1250-1265, 1998.

Ferrari, G. M.: The relationship between chromophoric dissolved organic matter and dissolved organic carbon in the European Atlantic coastal area and in the West Mediterranean Sea (Gulf of Lions), Mar. Chem., 70, 339-357, 2000.

Franz, B. A., Bailey, S. W., Werdell, P. J., and McClain, C. R.: Sensor-independent approach to the vicarious calibration of satellite ocean color radiometry, Appl. Opt., 46, 5068-5082, 2007.

Fu, G., Baith, K. S., and McClain, C. R.: SeaDAS: The SeaWiFS Data Analysis System. Proceedings of the 4th Pacific Ocean Remote Sensing Conference, Qingdao, China, 28-31 July 1998, 73-79, 1998.

Halpern, B. S., Walbridge, S., Selkoe, K. A., Kappel, C. V., Michelo, F., D’Agrosa, C., Bruno, J. F., Casey, K. S., Ebert, C., Fox, H. E., Fujita, R., Heinemann, D., Lenihan, H. S., Madin, E. M. P., Perry, M. T., Selig, E. R., Spalding, M., Steneck, R., and Watson, R.: A global map of human impact on marine ecosystems, Science, 319, 948-952, 2008.

Harris, C. K., Sherwood, C. R., Signell, R. P., Bever, A. J., and Warner, J. C.: Sediment dispersal in the northwestern Adriatic Sea, J. Geophys. Res., 113, C11S03, doi:10.1029/2006JC003868, 2008

Hooker, S. B., Esaias, W. E., Feldman, G. C., Gregg, W. W., and McClain, C. R.: An overview of SeaWiFS and ocean color, NASA Technical Memorandum, 1992-104566, 1, 1-24, edited by: Hooker, S. B. and Firestone, E. R., NASA-GSFC, Greenbelt, Maryland, 1992.

IOCCG: Remote sensing of inherent optical properties: Fundamentals, tests of algorithms, and applications. Reports of the International Ocean Colour Coordinating Group, Number 5, edited by: Lee, Z.-P. 126 pp., IOCCG, Dartmouth, Canada, 2006.

Lee, Z. P., Carder, K. L., Marra, J., Steward, R. G., and Perry, M. J.: Estimating primary production at depth from remote sensing, Appl. Opt., 35, 463-474, 1996.

Lee, Z. P., Carder, K. L., Arnone, R. A.: Deriving inherent op- tical properties from water color: a multiband quasi-analytical algorithm for optically deep waters, Appl. Opt., 41, 5755-5772, 2002.

Lee, Z. P., Weidemann, A., Kindle, J., Arnone, R., Carder, K. L., and Davis, C.: Euphotic zone depth: Its derivation and implicaton to ocean color remote sensing, J. Geophys. Res., 112, C03009, doi:10.1029/2006JC003802, 2007.

Loisel, H., Nicolas, J.-M., Deschamps, P.-Y., and Frouin, R.: Seasonal and inter-annual variability of particulate organic matter in the global ocean, Geophys. Res. Lett., 29, 2196, doi:10.1029/2002GL015948, 2002.

Lotze, H. K., Lenihan, H. S., Bourque, B. J., Bradbury, R. H., Cooke, R. G., May, M. C., Kidwell, S. M., Kirby, M. X., Peterson, C. H., and Jackson, J. B. C.: Depletion, degradation, and recovery potential of estuaries and coastal seas, Science, 312, 1806-1809, 2006.

Marini, M., Jones, B. H., Campanelli, A., Grilli, F., and Lee, C. M.: Seasonal variability and Po River plume influence on biochemical properties along western Adriatic coast, J. Geophys. Res., 113, C05S90, doi:10.1029/2007JC004370, 2008.

Marini, M., Grilli, F., Guarnieri, A., Jones, B. H., Klajic, Z., Pinardi, N., and Sanxhaku, M.: Is the southeastern Adriatic Sea coastal strip an eutrophic area? Estuarine, Coast. Shelf Sci., 88, 395406, 2010.

Maritorena, S., Hembise Fanton d'Andon, O., Mangin, A., Siegel, D. A.: Merged satellite ocean color data products using a biooptical model: Characteristics, benefits and issues, Remote Sens. Environ., 114, 1791-1804, 2010.

Mauri, E. and Poulain, P.-M.: Northern Adriatic Sea surface circulation and temperature/pigment fields in September and October 1997, J. Mar. Syst., 29, 51-67, 2001.

Mélin, F., Zibordi, G., and Berthon, J.-F.: Assessment of SeaWiFS atmospheric and marine products for the Northern Adriatic Sea, IEEE Trans. Geosci. Remote Sens., 41, 548-558, 2003.

Mélin, F., Clerici, M., Zibordi, G., Bulgarelli, B.: Aerosol variability in the Adriatic Sea from automated optical field measurements and SeaWiFS, J. Geophys. Res., 111, D22201, doi:10.1029/2006JD007226, 2006.

Mélin, F. and Zibordi, G.: An optically-based technique for producing merged spectra of water leaving radiances from ocean color, Appl. Opt., 46, 3856-3869, 2007.

Mélin, F., Zibordi, G., and Berthon, J.-F.: Assessment of satellite ocean color products at a coastal site, Remote Sens. Environ., 110, 192-215, 2007a.

Mélin, F., Zibordi, G., and Djavidnia, S.: Development and validation of a technique for merging satellite derived aerosol optical depth from SeaWiFS and MODIS, Remote Sens. Environ., 108, 436-450, 2007b.

Mélin, F., Zibordi, G., and Djavidnia, S.: Merged series of normalized water leaving radiances obtained from multiple satellite missions for the Mediterranean Sea, Adv. Space Res., 43, 423437, 2009.

Mélin, F.: Global distribution of the random uncertainty associated with satellite derived Chl $a$, IEEE Geosci. Remote Sens. Lett., 7, 220-224, 2010.

Mélin, F., Vantrepotte, V., Clerici, M., D’Alimonte, D., Zibordi, G., Berthon, J.-F., and Canuti, E.: Multi-sensor satellite time series of optical properties and chlorophyll $a$ concentration in the Adriatic Sea, Prog. Oceanogr., doi:10.1016/j.pocean.2010.12.001, in 
press, 2011.

Mozetič, P., Solidoro, C., Cossarini, G., Socal, G., Precali, R., Francé, J., Bianchi, F., De Vittor, C., Smodlaka, N., and Fonda Umani, S.: Recent trends towards oligotrophication of the northern Adriatic: Evidence from chlorophyll $a$ time series, Est. Coast., 33, 362-375, 2010.

Penna, N., Capellacci, S., and Ricci, F.: The influence of the Po River discharge on phytoplankton bloom dynamics along the coastline of Pesaro (Italy) in the Adriatic Sea, Mar. Pollut. Bull., 48, 321-326, 2004.

Santoleri, R., Banzon, V., Marullo, S., Napolitano, E., D’Ortenzio, F., Evans, R.: Year-to-year variability of the phytoplankton bloom in the southern Adriatic Sea (1998-2000): Sea-viewing Wide Field-of-view Sensor observations and modeling study. J. Geophys. Res., 108, 8122, doi:10.1029/2002JC001636, 2003.

Solidoro, C., Bastianini, M., Bandelj, V., Codermatz, R., Cossarini, G., Canu, D. M., Ravagnan, E., Salon, S., and Trevisani, S.: Current state, scales of variability, and trends of biogeochemical properties in the northern Adriatic Sea, J. Geophys. Res., 114, C07S91, doi:10.1029/2008JC004838, 2009.

Vantrepotte, V. and Mélin, F.: Temporal variability in SeaWiFS derived apparent optical properties in European seas, Cont. Shelf Res., 30, 319-334, 2010.

Zanchettin, D., Traverso, P., and Tomasino, M.: Po River discharges: A preliminary analysis of a 200 -year time series, Clim. Change, 89, 411-433, 2008.

Zavatarelli, M., Raicich, F., Bregant, D., Russo, A., and Artegiani, A.: Climatological biogeochemical characteristics of the Adriatic Sea, J. Mar. Syst., 18, 227-263, 1998.
Zhang, C., Hu, C., Shang, S., Müller-Karger, F., Li, Y., Dai, M., Huang, B., Ning, X., and Hong, H.: Bridging between SeaWiFS and MODIS for continuity of chlorophyll-a concentration assessments off Southeastern China, Remote Sens. Environ., 102, 250 263, 2006.

Zibordi, G., Berthon, J.-F., Doyle, J.-P., Grossi, S., van der Linde, D., and Targa, C., Alberotanza, L.: Coastal Atmosphere and Sea Time Series (CoASTS): A tower-based, long-term measurement program. NASA Technical Memorandum 2002-206892, 19, 129, edited by: Hooker, S. B. and Firestone, E. R., NASA-GSFC, Greenbelt, Maryland, 2002.

Zibordi, G. Mélin, F., Hooker, S. B., D’Alimonte, D., and Holben, B. N.: An autonomous above-water system for the validation of ocean color radiance data, IEEE Geosci. Remote Sens. Lett., 42, 401-415, 2004.

Zibordi, G., Berthon, J.-F., Mélin, F., D’Alimonte, D., and Kaitala, S.: Validation of satellite ocean color primary products at optically complex coastal sites: northern Adriatic Sea, northern Baltic Proper and Gulf of Finland, Remote Sens. Environ., 113, 2574-2591, 2009.

Zibordi, G., Holben, B. N., Mélin, F., D’Alimonte, D., Berthon, J.F., Slutsker, I., and Giles, D.: AERONET-OC: An overview, Can J. Remote Sens., 36, 488-497, 2010.

Zibordi, G., Berthon, J.-F., Mélin, F., and D'Alimonte, D.: Crosssite consistent in situ measurements for satellite ocean color applications: The BiOMaP radiometric dataset, Remote Sens. Environ., 115, 2104-2115, 2011. 